\title{
CLUTCH SIZE, BREEDING SUCCESS, AND PARENTAL SURVIVAL IN THE TREE SWALLOW (IRIDOPROCNE BICOLOR)
}

\author{
Diane De Steven \\ Museum of Zoology and Department of Ecology and Evolutionary Biology, \\ University of Michigan, Ann Arbor, Michigan 48109
}

Received November 13, 1978. Revised October 5, 1979

Lack (1947) hypothesized that clutch size in nidicolous birds has evolved by natural selection to correspond with the maximum number of young that, on average, the parents can feed. Although the hypothesis gained wide acceptance in subsequent years, the evidence is equivocal and inconsistencies remain (Klomp, 1970; Cody, 1971; von Haartman, 1971; Hussell, 1972). Those cases in which the most productive brood size is larger than the most common do not support the implied concept of direct limitation of clutch size by food supply. Furthermore, the interpretation of brood manipulation experiments that support Lack's hypothesis is open to question, since the results do not distinguish between food supply limits in the environment and possible adaptive limits upon parental feeding behavior (Cody, 1971; Hussell, 1972). Mountford (1968) suggested that incorrect formulation of predictions was responsible for some apparent contradictions.

Lack recognized that selection should favor the clutch size that maximizes fitness, but overemphasized the direct influence of environmental factors upon clutch size as a single trait. A more comprehensive perspective incorporates interactions between clutch size and other life history features as well (Fisher, 1958; see review in Stearns, 1976). Pertinent models predict a most common clutch that is smaller than the most productive, under the assumption that rearing larger broods places greater stress upon parents and reduces their chances of surviving to breed again (Williams, 1966; Charnov and Krebs, 1974).

The assumption of a trade-off between clutch size and adult survivorship within populations is largely untested. Observations from naturally occurring brood sizes have not yielded any consistent relationship between clutch size and parental survival (e.g., Kluyver, 1963; Perrins, 1965; Lack, 1966, p. 109). However, since variation in parental ability (e.g., efficiency in gathering food for egg formation or for feeding nestlings) may contribute to adaptive modification of clutch size (cf. Klomp, 1970), the search for such a relationship is confounded. If parents that normally initiate larger clutches are more capable of rearing them, the young in those broods are not necessarily disadvantaged (cf. Perrins and Moss, 1975), nor are those parents necessarily less likely to survive than parents raising smaller broods. Greater weight losses among parents with larger broods (Hussell, 1972; Winkel and Winkel, 1976; Bryant, 1979) and lower probabilities of initiating a second brood after a large first brood (Kluyver, 1963; Pinkowski, 1977) provide indirect evidence that rearing large broods is stressful physiologically, but have yet to be linked to differential survival. Recently, Bryant (1979) found differences in survival between single- and double-brooded female House Martins (Delichon urbica), but these differences were not related to the brood sizes reared.

Experimental approaches to testing the hypothesis that birds adaptively limit clutch size for the sake of enhanced survival are likely to provide the strongest inferences (cf. Ricklefs, 1973, p. 426; Stearns, 1976, p. 42). Artificial manipulation can extend brood sizes beyond limits currently observed within a population. However, if parental ability is reflected in individual clutch sizes, parents 
must receive clutches enlarged in relation to the sizes they originally attempted and must be compared to parents whose clutches are not altered in size. This approach tests more directly for a relationship between increased parental effort and survival than does the random assignment of brood sizes to parents that has characterized previous studies (cf. Perrins and Moss, 1975) and that tests for average ability to rear young under a particular set of environmental conditions.

I report an attempt to test the hypothesis of an interaction between clutch size and parental survival in the Tree Swallow, Iridoprocne bicolor. Among known sources of phenotypic variation in clutch size in this species (cf. Kuerzi, 1941), yearling females lay smaller clutches than do females two years and older (De Steven, 1978). Age-specific differences in clutch size have generally been regarded as an adaptive modification that adjusts for the inexperience of new breeders (cf. Klomp, 1970). Interpretation in the context of life history theory suggests the hypothesis that by raising smaller broods and exerting less effort, young individuals are holding their own probability of survival high (Perrins and Moss, 1974; see also Pianka and Parker, 1975). I tested this subsidiary hypothesis as well by enlarging broods of both female age groups and comparing them to each other as well as to controls of both age classes.

I evaluate the females' breeding performance and its subsequent effects upon their condition and survival. The hypothesis of environmental limitation of clutch size (sensu Lack) would predict slower nestling growth, lower fledging success, and/or poorer survival of young from enlarged broods than from normal-sized broods. The cost-of-reproduction hypothesis would predict greater weight losses (cf. Ricklefs, 1974, p. 261) and/or lower survival for females raising enlarged broods as a result of increased stress. Inability to rear extra young or inability to tolerate reproductive stress might be more pronounced in yearling females than in older females. Methods of analysis distin- guish sources of variation within and among broods in addition to evaluating age and treatment effects.

\section{Methods}

Bird.-The Tree Swallow is an amenable subject for manipulative studies because it readily uses nest boxes, breeds repeatedly in the same colonies, and tolerates considerable disturbance at the nest without deserting. A detailed natural history is given in Kuerzi (1941); here it is appropriate to point out several features. Normally only one brood is reared per year. The breeding system is monogamous, although several times I have trapped individual males feeding nestlings at two different nests (usually in adjacent nest boxes). Thus there may be occasional polygyny, but all of the males included in this study were monogamous. Males assist females in nest building, nest defense, and feeding nestlings, but not in incubating eggs. Because many aspects of male biology are not well known (e.g., age and agerelated fecundity and success) and because males are not trapped as easily as females, the experiments in this study were designed with respect to and results evaluated for females only.

Study site.- I conducted this study in 1976 on Long Point, Ontario, a large sandspit extending $29 \mathrm{~km}$ eastward from the northern shore of Lake Erie. The extreme eastern end of the Point is characterized by early dune successional vegetation (cf. Cowles, 1901) amid both permanent and temporary ponds, a habitat that provides a rich food source of emerging aquatic insects for aerial-foraging birds and that appears similar to natural Tree Swallow nesting areas (Forbush and May, 1939; Palmer, 1949). A nest-box colony for Tree Swallows has been maintained in this area since 1969 by the Long Point Bird Observatory (LPBO), which collects nest-record data and supervises annual banding of adults and young. In 1976, 91 of the 134 available nest boxes were occupied by nesting Tree Swallow pairs.

Brood-size experiments. - Tree Swal- 
TaBle 1. Design for Tree Swallow brood-size experiments.

\begin{tabular}{lc}
\hline \multicolumn{1}{c}{ Brood category } & $\begin{array}{c}\text { Brood sizes } \\
\text { represented }\end{array}$ \\
\hline Control: Yearling $q$ & $5^{\mathrm{a}}, 6$ \\
Control: Older $\$$ & $6^{\mathrm{a}}, 7$ \\
Experimental: Yearling $q$ & 7,8 \\
Experimental: Older $q$ & 8,9 \\
\hline
\end{tabular}

${ }^{a}$ Most common clutch for the age group (De Steven, 1978).

low nests were visited daily during the laying period to determine precise laying dates and clutch sizes for each pair. The age of the female (yearling or older) was also ascertained by observation of plumage during this time (cf. Kuerzi, 1941, on plumage differences between yearling and older females; see also De Steven, 1978). Daily visits were resumed close to the hatching time of each brood to determine hatch dates and ages for individual nestlings. In each brood used in the study, all nestlings were individually marked on the day of hatching by clipping the tip of one claw in a prearranged sequence. Nestlings added to experimental broods (see below) were marked so as to be distinguishable from the original nestlings of those broods. The clips required one renewal when the young were about three days old and subsequently remained visible until the young were banded with U.S. Fish and Wildlife Service bands at 12 days of age.

A control and an experimental category were designated for broods of both yearling and older female parents. In control broods, nestlings were added only to replace hatching losses (dead eggs) so that brood size equalled original clutch size; these broods represent the clutch sizes commonly observed for each parental age group (cf. De Steven, 1978). In experimental broods, nestlings were added both to replace hatching losses and to increase the original clutch sizes of each pair by two young. The result was an overall range of brood sizes from five to nine ( $\mathrm{Ta}$ ble 1). All transfers were performed within one day (occasionally two days) after hatching, and only nestlings that had hatched on the same day(s) as the young in a recipient brood were transferred to that brood.

Rather than repeatedly disturbing the broods in order to construct curves for nestling growth, I compared weights and primary feather lengths attained at specific ages as a means for assessing rapidity of growth and the size and condition of nestlings. Since hatching is sometimes asynchronous in clutches of six or seven, growth data for nestlings in such broods were taken on different days in order to make the ages of measurement equivalent. Weights were taken to the nearest $0.1 \mathrm{~g}$ with a Pesola spring balance at 3,13 , and 16 days of age, and the length of the outer primary feather from sheath base (where it emerges from the skin) to feather tip was measured to the nearest $\mathrm{mm}$ at 13 and 16 days also. There is no external feather development at three days of age. Three days was chosen partly for convenience, as it was necessary to renew the temporary claw marks, and partly for an early assessment of growth. Thirteen days is the approximate age of a peak in weight for nestling Tree Swallows (Paynter, 1954), after which weight declines to adult levels as a probable result of water losses accompanying feather maturation (Ricklefs, 1968). Measurements at 16 days estimate the size and condition of the young near fledging. It is the latest age at which measurements can be obtained without risk of premature fledging, since the young are capable of limited flight prior to the normal fledging age of 18 to 20 days (Kuerzi, 1941). Brief visits to the nests after 16 days confirmed final fledging dates for the broods. Those nests that had provided the additional nestlings for the experiments were followed only for purposes of banding and confirmation of fledging, and no growth data were taken.

Broods chosen for the study hatched during the main breeding period of the colony and differed in hatching dates by only slightly more than a week (Fig. 1), thus minimizing the effects of seasonal variations in nesting success. Thirteen of the 17 completed clutches of yearling females were used in the study, the rest 
being late nests. Of the 72 completed clutches of older females, 34 were initially used for the study, five hatched either too early or too late, and the remaining 33 provided the additional nestlings for transfer. Normally two or three young were left in the donor nests to prevent desertion by the parents.

Metal shields were placed around the nest-box poles to exclude predators; however, six broods were still partially or wholly preyed upon by snakes after the study had commenced. These broods were not included in the analyses.

Parents.-Since the females roost on the nest at night for about one week after the young hatch, each could be caught and weighed easily once on the first night of her brood's hatching and again five nights later. This permitted standardization of weighing times from the first to the second, since body weight can vary widely with time of day (Baldwin and Kendeigh, 1938). Females were weighed to the nearest $0.5 \mathrm{~g}$ with a Pesola spring balance. In a few cases, females had ceased brooding by the sixth night and a second weight was not obtained. Most male parents were captured once for identification and banding; however, no male was caught at four of the study nests, perhaps indicating male desertion.

Survivorship.- To determine returns of adults and especially young from the 1976 study, in 1977 and 1978 nearly all breeding adults were captured while feeding nestlings. Two consecutive years of trapping effort are important for recovery of fledglings of a given year, since some may return to the colony in their second year but fail to breed there until their third year. In contrast, fewer adults skip breeding in the colony between years. Among the group under study in 1976, no females were recovered in 1978 that had not returned in 1977.

Return rates are minimum estimates of survival, since emigration and death are indistinguishable.

Statistics.-Data analysis was performed with use of statistical programs from the Michigan Interactive Data Anal-

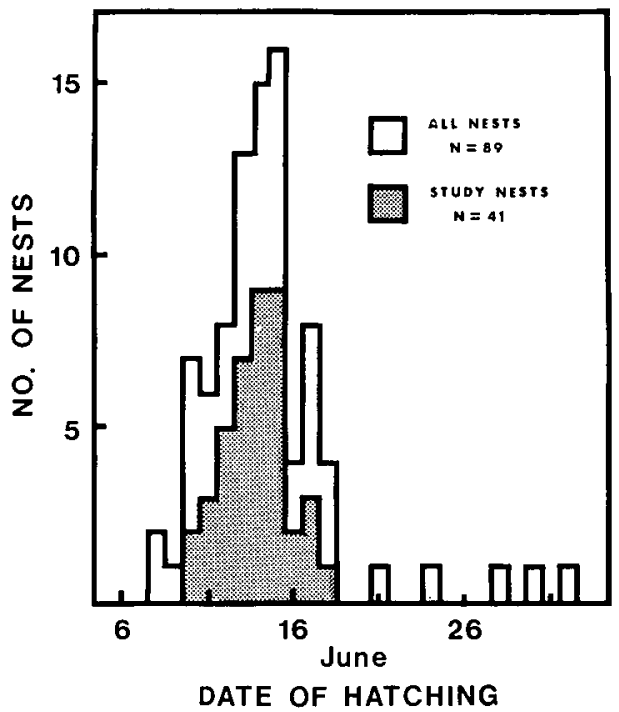

FIG. 1. Hatching dates of Tree Swallow broods selected for study in relation to the hatching period of the Long Point colony in 1976.

ysis System (MIDAS). Significant results were those giving a probability of Type I error of $5 \%$ or less.

Analysis of nestling growth presents special problems. A set of growth measurements normally contains several sources of variation: 1) that from nestlings within a single brood, 2) that from broods of a given size reared by different parents, and 3) that from different brood sizes. Surprisingly, few studies of nestling growth have taken all these sources of variation into account. Either the first is ignored and the measurements are averaged for each brood, or the second is ignored and all measurements from a given brood size are combined. Either approach may seriously bias any subsequent tests of the effects of brood size on nestling growth. An analysis that evaluates all sources of variation is both more correct and more informative.

The experiments in this study introduce two additional sources of variation: parental age class and "treatment" effect (control vs. experimental). Since these are not independent of brood-size variation, the analysis is simplified; nevertheless the requirements of a model allowing simulta- 
TABLE 2. Breeding success $( \pm S D)$ of Tree Swallow study broods.

\begin{tabular}{|c|c|c|c|c|}
\hline Category & Brood size & No. of nests & $\begin{array}{l}\text { Mean no. of } \\
\text { fledged young }\end{array}$ & $\begin{array}{l}\text { Mean fledging } \\
\text { rate }(\%)^{\mathrm{a}}\end{array}$ \\
\hline Control: & 5 & 2 & $5.0 \pm 0.0$ & $100.0 \pm 0.0$ \\
\hline \multirow{2}{*}{ Yearling 9} & 6 & 3 & $5.7 \pm 0.6$ & $94.4 \pm 9.6$ \\
\hline & Comb. & 5 & & $96.7 \pm 3.3$ \\
\hline \multirow{3}{*}{$\begin{array}{l}\text { Control: } \\
\text { Older } q\end{array}$} & 6 & 10 & $5.9 \pm 0.3$ & $98.3 \pm 5.3$ \\
\hline & 7 & 5 & $6.6 \pm 0.5$ & $94.3 \pm 7.8$ \\
\hline & Comb. & 15 & & $97.0 \pm 1.6$ \\
\hline \multirow{3}{*}{$\begin{array}{c}\text { Experimental: } \\
\text { Yearling } 9\end{array}$} & 7 & 3 & $6.3 \pm 0.6$ & $90.5 \pm 8.2$ \\
\hline & 8 & 4 & $7.8 \pm 0.5$ & $96.9 \pm 6.2$ \\
\hline & Comb. & 7 & & $94.1 \pm 2.8$ \\
\hline \multirow{3}{*}{$\begin{array}{l}\text { Experimental: } \\
\text { Older } \%\end{array}$} & 8 & 8 & $7.5 \pm 0.8$ & $93.8 \pm 9.4$ \\
\hline & 9 & 6 & $8.3 \pm 0.8$ & $92.6 \pm 9.1$ \\
\hline & Comb. & 14 & & $93.2 \pm 2.4$ \\
\hline
\end{tabular}

a $G$-test (Sokal and Rohlf, 1969, p. 601) on combined categories (Comb.) $=4.14, d . f .=4, P>.10$ (n.s.).

neous evaluation of both factors were not met by the data. I performed separate analyses in parallel for the two age groups of females and used brood size as the main effect; the resulting model is a one-way nested (hierarchical) analysis of variance (cf. Sokal and Rohlf, 1969, p. 253). Using brood size in this manner incorporates the "treatment" of brood enlargement. The model represents the best approximation given that data collected under field conditions often fail to meet all the criteria of statistical models. Graphical presentations summarize the data and permit visual inspection.

\section{RESULTS}

\section{Breeding Performance}

Overall nesting success of female Tree Swallows in each of the brood categories is summarized in Table 2. Productivity figures are subdivided according to brood size and show clearly that the largest broods fledge the most young. Even though yearling females normally fledge fewer young than older females because of their smaller average clutch size (De Steven, 1978), they can successfully rear additional young.

The slightly lower average fledging rates from experimental broods relative to control broods suggest some negative effect of brood enlargement, even though the differences are not significant (Table 2). The increased incidence of mortality should be the result of starvation if food supply or parental feeding response is inadequate for rearing larger than normal broods. I analyzed nestling mortality in more detail and considered starvation a probable cause of death if a nestling died at an early age ( $\leqslant 3$ days old) or was obviously underweight relative to its siblings at the last weighing prior to death. One control nest and four experimental nests showed evidence of starvation, but these account for only five of the 13 nests in which deaths occurred. Nestlings that died were not necessarily transferred young (4 of 15 deaths) nor late-hatched young ( 6 of 15). In many instances there was no obvious reason for death.

The consistently low total mortality as reflected in mean fledging rates greater than $90 \%$ shows that food stress, if it existed, was not sufficient to prevent the fledging of most young regardless of brood category.

\section{Nestling Growth}

As Perrins (1965) has shown for the Great Tit (Parus major), the number of fledged young is an incomplete measure of reproductive success, since the condition of the young at fledging may influence subsequent survival. Nestlings in enlarged Tree Swallow broods may suffer retarded 
growth if food supply or parental feeding ability is limiting (but not severely) and may have poorer chances of survival after leaving the nest.

Primary feather growth was thought to be a meaningful index of overall nestling growth rate, since swallows do not fledge until adequate flight capability is attained. Primary measurements for 13- and 16-day old nestlings are presented in summary form in Figure 2. Most obvious is the large variability in growth. Overall, "experimental" nestlings are significantly more variable in primary length than "control" nestlings ( $F$ test for equality of variances, $P<.001$ for all four combinations of nestling age and parental age class). Minimum measurements also ranged much lower in experimental broods. When the data are partitioned for the nested ANOVA, a less obvious result emerges. There is no significant influence of brood size upon nestling growth; most of the variation is due to differences in average growth among individual broods of a given size (Table 3). Thus experimental broods did not show poorer average growth but rather greater variability in growth. Membership in a particular brood was more important than was the size of the brood.

Greater variability in growth implies that young in at least some experimental broods were growing more slowly. If fledging age remains constant, a small primary feather length at 16 days would indicate a disadvantage in size at fledging. However, duration of the nestling period for each brood (computed as the time from hatching to final fledging of all young) is inversely related to mean primary length for each brood at 16 days $(r=-0.71, N=$ $38, P<.01)$. The nestling period is probably overestimated slightly where the members of a brood do not fledge simultaneously, but it was not feasible to record time in the nest for individual young. Since the occurrence of unusually windy and cool weather from July 1 to 3 may have delayed fledging of some broods that would normally have left the nest during that time, I repeated the analysis for only those broods due to fledge after July 4.

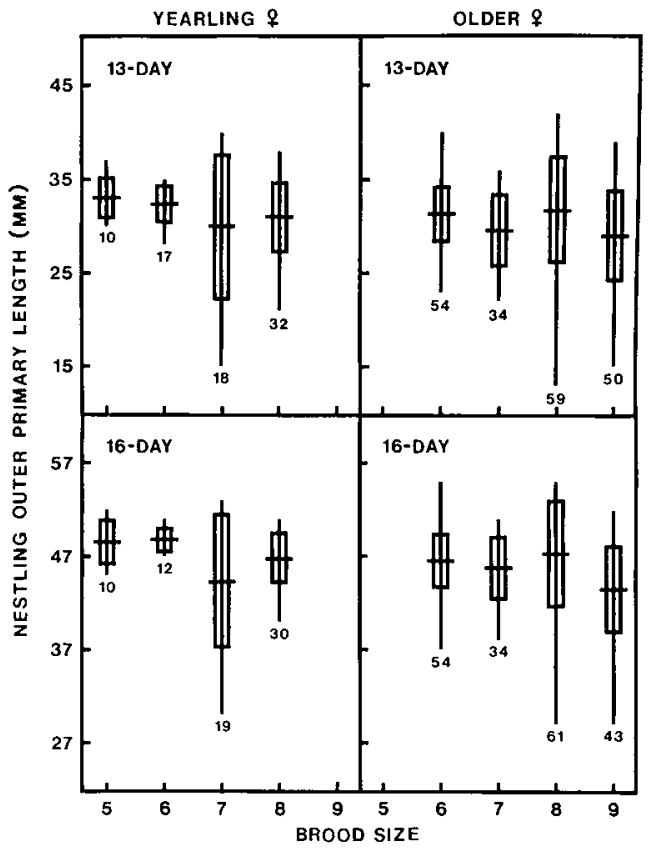

FIG. 2. Outer primary feather lengths of Tree Swallow nestlings at 13 and 16 days of age in relation to brood size. Data are presented separately for broods reared by yearling females and by older females. Within each age category, the two smaller brood sizes are control broods and the two larger brood sizes are the experimental broods created by addition of two young each to control brood sizes (cf. Methods). Vertical line represents the range, horizontal line the mean, and rectangle one standard deviation on either side of the mean. Sample size (number of nestlings) is given below each symbol.

The relationship still holds $(r=-0.81$, $N=15, P<.01)$. Thus, those young exhibiting slower primary feather growth remained longer in the nest while, presumably, making up their growth deficit.

Even if Tree Swallow young in enlarged broods may attain adequate size (as reflected in primary feather growth) at fledging, they may be lower in weight and in poorer condition. Nestling weight variation may reflect variation in fat stores (cf. O'Connor, 1976), which may in turn influence survival after leaving the nest (e.g., Perrins, 1965; Howe, 1976). Weights of Tree Swallow nestlings at three, 13, and 16 days of age are presented in summary form in Figure 3. Among broods 
TABLE 3. Analyses of variance for nestling outer primary lengths in Tree Swallow study broods.

\begin{tabular}{|c|c|c|c|c|c|c|c|c|}
\hline \multirow[b]{2}{*}{ Source } & \multicolumn{4}{|c|}{ Yearling females } & \multicolumn{4}{|c|}{ Older females } \\
\hline & SS & d.f. & $M S$ & $F$ & SS & $d . f$. & $M S$ & $F$ \\
\hline & \multicolumn{8}{|c|}{ Thirteen-day primary length } \\
\hline Brood size & 85.1 & 3 & 28.4 & 0.2 & 263.2 & 3 & 87.7 & 0.7 \\
\hline Broods within brood size & $1,156.6$ & 8 & 144.6 & $20.3 * *$ & $2,930.7$ & 24 & 122.1 & $17.0^{* *}$ \\
\hline Nestlings within broods & 461.9 & 65 & 7.1 & & $1,210.1$ & 169 & 7.2 & \\
\hline \multirow[t]{2}{*}{ Total nestlings } & $1,703.6$ & 76 & & & $4,404.0$ & 196 & & \\
\hline & \multicolumn{8}{|c|}{ Sixteen-day primary length } \\
\hline Brood size & 190.5 & 3 & 63.5 & 0.5 & 397.2 & 3 & 132.4 & 1.1 \\
\hline Broods within brood size & 835.2 & 7 & 119.3 & $20.9^{* *}$ & $2,848.2$ & 23 & 123.8 & $20.6 * *$ \\
\hline Nestlings within broods & 341.1 & 60 & 5.7 & & 985.3 & 165 & 6.0 & \\
\hline Total nestlings & $1,366.8$ & 70 & & & $4,230.7$ & 191 & & \\
\hline
\end{tabular}

$* * P \leqslant .01$.

reared by yearling females, a tendency for lower nestling weights in larger broods appears as early as three days of age, although at this stage the differences among brood sizes are not significant (Table 4). However, by 13 days, young in broods of five attain significantly higher peak weights than young in all larger broods, and this difference is maintained as the young approach fledging age (Table 4 and Fig. 3). The nested analysis of variance (Table 4) shows that the high interbrood variation that characterized primary feather growth does not occur in the weights attained in these broods. Tendencies for slower growth in experimental broods are also reflected in the failure of 11 nestlings from three different enlarged broods to reach peak weights at 13 days.

In contrast to broods reared by yearling females, nestling weights in broods reared by older females show large variability but no clear trends with respect to brood size (Fig. 3). The nested analysis of variance shows most of the variation to be due to differences among individual broods (Table 4). Only at 16 days of age is there a suggestion of a decline in weight with increasing brood size, but this may be due to a number of nestlings in broods of six that continued to increase in weight from 13 to 16 days. Emphasizing the large variation in weights in these broods, 12 young from 4 control broods and 9 young from 4 experimental broods had failed to reach peak weights at 13 days of age. In general, variation in weights was not consistently larger in the experimental categories as compared to the control categories ( $F$ test, $P>.10$ at 3 and 16 days) and at 13 days the reverse was true $(F=1.45 ; d . f .=87$, 109; $P<.05$ ).

After 16 days, nestling weights may continue to decline if peak weights were attained slowly, or they may stabilize at adult levels (cf. Methods). While an extension of the nestling period may allow feather maturation to be completed, the differences in weight are unlikely to change appreciably and may even become accentuated as weight recession is completed in more slowly growing broods. Thus, observed differences in weight at 16 days estimate differences in the condition of the young at fledging several days later. Brood enlargement influenced fledging weights negatively among broods reared by yearling females, but not among broods reared by older females.

\section{Fledgling Survivorship}

Reproductive success should also be evaluated in terms of the survival of young to breeding age, but this is often the factor for which the least information is available. While $30-40 \%$ of adult Tree Swallows may return annually to the Long Point colony, return rates for juveniles fledged from the colony are in the order of 5-10\% (D. Hussell, pers. comm.; De Steven, 1978). The low number of returning juveniles probably reflects dispersal to 
other breeding sites as well as high postfledging mortality (Chapman, 1935). Assuming that every surviving Tree Swallow juvenile is equally likely to return to the breeding colony, return rates will estimate survivorship. Since all fledglings from the 1976 experiments hatched within a limited time period (Fig. 1), seasonal variations in survival probabilities should be minimal (cf. De Steven, 1978).

Of 417 young fledged from the colony, $27(6.5 \%)$ returned in 1977 and/or 1978. Two of the 27 were not recovered in the study colony but instead in another colony under LPBO supervision approximately $29 \mathrm{~km}$ distant. Fourteen returns were from broods used in the study. From these recoveries it appears that enlarged broods recruited young as well as normal-sized broods; half of the 14 had come from broods of eight (Table 5). Among the study broods, $6.5 \%$ of the young reared by yearling females were recovered in contrast to $4.5 \%$ of the young of older females $\left(\chi^{2}=0.14, d . f .=1, P>.10\right)$. From the 23 broods that were eventually reduced in size to provide extra nestlings for the experiments, $13.5 \%$ of the young fledged returned to the colony $(N=52)$. Most of these broods contained two or three young, and recruitment from these may be particularly high.

Mean 16-day primary lengths for the broods that recruited young averaged no higher than those for broods from which no young returned $(t=0.84, d . f .=36$, $P>.10)$, nor did mean 16-day weights differ between the two groups $(t=0.78$, $d . f .=36, P>.10)$. Thus young that returned did not come from broods that grew most slowly, but neither did they necessarily come from broods that grew fastest or were heaviest near fledging.

\section{Female Weight Loss and Survivorship}

Weight losses of female parents during the first part of the nestling period are presented in Table 6. Although the differences were not significant, there was a tendency for females raising enlarged broods to lose more weight than females raising normal-sized broods, and, within

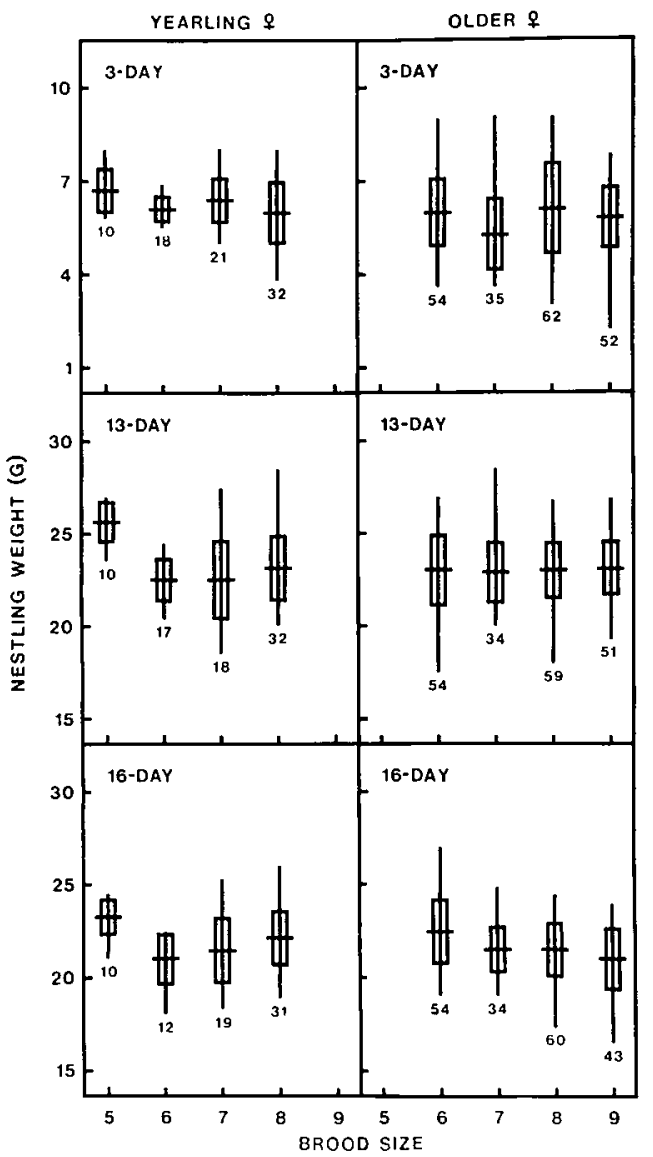

FIG. 3. Weights of Tree Swallow nestlings at 3, 13 , and 16 days of age in relation to brood size. Data are presented separately for broods reared by yearling females and by older females. Interpretation of symbols as in Fig. 2.

a treatment category, for yearlings to lose more weight than older females. Analysis of weight loss as a percentage of initial weight produced the same results, indicating that initial weights had been similar in every category. Percent loss was thus proportional to net loss. Among nine older females whose broods had been reduced in size to provide extra nestlings for the experiments, weight losses averaged 1.1 $\mathrm{g}(\mathrm{SE}=0.2)$ and did not differ significantly from the losses of older females in the two treatment categories $(F=1.52$; d.f. $=2,31 ; P>$.10).

If these losses do reflect physiological 
TABLE 4. Analyses of variance for nestling weights in Tree Swallow study broods.

\begin{tabular}{|c|c|c|c|c|c|c|c|c|}
\hline \multirow[b]{2}{*}{ Source } & \multicolumn{4}{|c|}{ Yearling females } & \multicolumn{4}{|c|}{ Older females } \\
\hline & $s S$ & $d . f$. & $M S$ & $F$ & $S S$ & $d f$. & $M S$ & $F$ \\
\hline & \multicolumn{8}{|c|}{ Three-day weight } \\
\hline Brood size & 5.3 & 3 & 1.8 & 2.2 & 17.5 & 3 & 5.8 & 1.1 \\
\hline Broods within brood size & 6.9 & 8 & 0.8 & 1.3 & 126.5 & 24 & 5.3 & $6.6 * *$ \\
\hline Nestlings within broods & 44.7 & 69 & 0.6 & & 131.6 & 175 & 0.8 & \\
\hline \multirow[t]{2}{*}{ Total nestlings } & 56.9 & 80 & & & 275.6 & 202 & & \\
\hline & \multicolumn{8}{|c|}{ Thirteen-day weight } \\
\hline Brood size & 75.6 & 3 & 25.2 & $5.0^{*}$ & 1.6 & 3 & 0.5 & 0.05 \\
\hline Broods within brood size & 39.6 & 8 & 5.0 & 1.8 & 260.3 & 24 & 10.8 & $6.3^{* *}$ \\
\hline Nestlings within broods & 177.0 & 65 & 2.7 & & 299.0 & 170 & 1.7 & \\
\hline \multirow[t]{2}{*}{ Total nestlings } & 292.2 & 76 & & & 560.9 & 197 & & \\
\hline & \multicolumn{8}{|c|}{ Sixteen-day weight } \\
\hline Brood size & 36.5 & 3 & 12.2 & $7.2^{*}$ & 50.0 & 3 & 16.7 & 1.8 \\
\hline Broods within brood size & 12.2 & 7 & 1.7 & 0.7 & 213.8 & 23 & 9.3 & $5.8^{* * *}$ \\
\hline Nestlings within broods & 140.8 & 61 & 2.3 & & 259.2 & 164 & 1.6 & \\
\hline Total nestlings & 189.5 & 71 & & & 523.0 & 190 & & \\
\hline
\end{tabular}

$* .01<P \leqslant .05 ; * * P \leqslant .01$.

stress, the trends are at least consistent with the hypothesis that brood enlargement increases stress upon parents and that yearlings are less tolerant of this increase than older females. However, even the maximum difference in average loss between any two groups is less than $1 \mathrm{~g}$, although the largest average loss $(1.9 \mathrm{~g})$ is near $10 \%$ of body weight.

The final question is whether rearing

TABLE 5. Returns in 1977 or 1978 of Tree Swallows fledged from 1976 study broods.

\begin{tabular}{ccrcccc}
\hline Category & \multicolumn{1}{c}{$\begin{array}{c}\text { No. } \\
\text { Brood } \\
\text { size }\end{array}$} & $\begin{array}{c}\text { No. } \\
\text { young } \\
\text { broods fledged }\end{array}$ & $\begin{array}{c}\text { No. } \\
\text { retung } \\
(\%)^{\mathrm{a}}\end{array}$ & $\begin{array}{c}\text { No. re- } \\
\text { turned } \\
\text { per } \\
\text { brood }\end{array}$ \\
\hline Control: & 5 & 2 & 10 & 1 & 0.50 \\
Yearling 9 & 6 & 3 & 17 & 1 & 0.33 \\
& Comb. & 5 & 27 & $2(7.4)$ & \\
Control: & 6 & 10 & 59 & 2 & 0.20 \\
Older 9 & 7 & 5 & 33 & 1 & 0.20 \\
& Comb. & 15 & 92 & $3(3.3)$ & \\
Experimental: & 7 & 3 & 19 & 1 & 0.33 \\
Yearling 9 & 8 & 4 & 31 & 2 & 0.50 \\
& Comb. & 7 & 50 & $3(6.0)$ & \\
Experimental: & 8 & 8 & 60 & 5 & 0.62 \\
Older 9 & 9 & 6 & 49 & 1 & 0.17 \\
& Comb. & 14 & 109 & $6(5.5)$ & \\
\hline
\end{tabular}

a $G$-test on combined categories (Comb.) $=3.78$, d.f. $=4, P>.10$ (n.s.). enlarged broods influenced subsequent survival. Returns are presented for all females of the 1976 experiments as well as for that subset for which weights were successfully obtained (Table 7). Overall, $57.9 \%$ of the control females returned in contrast to $66.7 \%$ of the experimental females $\left(\chi^{2}=0.34, d . f .=1, P>.10\right)$. Yearlings had somewhat higher return rates $(72.7 \%)$ than older females $(58.6 \%)$ in general $\left(\chi^{2}=0.66, d . f .=1, P>.10\right)$, but these values may be inflated due to the smaller sample of yearlings. Among 23 females whose broods were reduced in size, $78.3 \%$ returned, and of the nine from that group that had been weighed, $56 \%$ returned.

TABLE 6. Weight losses of female parents of Tree Swallow study broods over a six-day period.

\begin{tabular}{lcc}
\hline \multicolumn{1}{c}{ Category } & $\begin{array}{c}\text { Mean weight } \\
\text { loss (g) } \\
\pm \mathrm{SE}\end{array}$ & $\begin{array}{c}\text { No. of } \\
\text { females }\end{array}$ \\
\hline Control: Yearling $q$ & $1.6 \pm 0.6$ & 4 \\
Control: Older $q$ & $1.3 \pm 0.2$ & 11 \\
Experimental: Yearling $q$ & $1.9 \pm 0.3$ & 5 \\
Experimental: Older $q$ & $1.6 \pm 0.2$ & 14 \\
\hline
\end{tabular}

ANOVA: $F$ (yearling vs. older) $=1.4 ; d . f .=1,30 ; P>.10$ (n.s.) $F$ (control vs. experimental) $=1.1 ; d . f .=1,30 ; P>.10($ n.s.). $F$ (interaction) $=0.01 ; d . f .=1,30 ; P>.10$ (n.s.). 
TABLE 7. Returns in 1977 of female parents of Tree Swallow study broods.

\begin{tabular}{|c|c|c|c|c|}
\hline \multirow[b]{2}{*}{ Category } & \multicolumn{2}{|c|}{ All females } & \multicolumn{2}{|c|}{ Females weighed } \\
\hline & $n$ & $\begin{array}{l}\text { No. returned } \\
(\%)\end{array}$ & $n$ & $\begin{array}{l}\text { No. returned } \\
(\%)\end{array}$ \\
\hline Control: Yearling $q$ & $4^{\mathrm{a}}$ & $3(75.0)$ & $3^{\mathrm{a}}$ & $2(67.0)$ \\
\hline Control: Older $q$ & 15 & $8(53.3)$ & 11 & $5(45.0)$ \\
\hline Experimental: Yearling 우 & 7 & $5(71.4)$ & 5 & $3(60.0)$ \\
\hline Experimental: Older 9 & 14 & $9(64.3)$ & 14 & $9(64.3)$ \\
\hline
\end{tabular}

${ }^{a}$ One female that had been weighed died from unknown causes just prior to the successful fledging of her brood. Her weight loss was not abnormal. This bird was omitted from the table.

\section{Discussion}

The increased productivity of enlarged broods, the variability in nestling quality among broods, and the absence of broodsize dependent mortality after fledging suggest that larger clutches in the Long Point population would not be limited by food availability, nor by the ability of at least some adults to rear additional young. These results are similar to those from studies of other passerines (e.g., von Haartman, 1967; Hussell, 1972; Bryant, 1975, Perrins and Moss, 1975) and do not conform to Lack's predictions. Each merits brief discussion.

The most productive brood size appears to be larger than the most common among naturally occurring Tree Swallow broods (Paynter, 1954; De Steven, 1978; but see Stocek, 1970), but in the present study productivity also increased as brood size was enlarged beyond the normal maximum of seven. This is probably not the result of unique conditions in 1976 . In two separate series of experiments performed at Long Point from 1970 to 1972 by M. Bradstreet and by D. Hussell, broods of eight and nine young were successfully reared to fledging despite yearly variations in weather conditions (and, presumably, in food supply) (Hussell, in LPBO Annual Reports 1970-72 and Hussell, pers. comm.). The question remains as to whether particularly unfavorable years that may limit optimal brood size occur more infrequently than the time span over which populations of this species have been studied to date. It is a pertinent question for other studies as well.
The effects of brood enlargement upon nestling growth were neither extreme nor consistent. Fledging weights were significantly lower in large broods reared by yearling females, but this was not true among broods reared by older females. Tendencies for slower growth in larger broods were in part compensated for by extended nestling periods. However, since nest predation was deliberately prevented, its potential selective importance in favoring rapid nestling growth and short nestling periods could not be assessed (cf. Perrins, 1977). Most interesting was the result that much of the variation in growth could be attributed to differences among individual broods. Variation among broods in the quality of young may reflect substantial variation in parental competence. The male parent's contribution is potentially important but could not be evaluated in detail in the present study. Of the four nests at which I could not capture and thus ascertain the presence of a male parent, three were experimental broods reared by older females, and two of these were among the slowest growing in that category. The other two broods, the third experimental and one control, showed average growth. In the House Martin, a similar swallow species, male feeding rates increased faster than female rates as brood size increased; additional evidence emphasized the importance of the male to successful breeding (Hails and Bryant, 1979).

There is no clear evidence of differential post-fledging mortality with respect to brood size, even for experimentally enlarged broods (cf. De Steven, 1978). How- 
ever, chance events may be important with juvenile return rates as low as $6 \%$, and more data on yearly variations in recruitment are needed. If conditions influencing juvenile survivorship are variable and unpredictable at the time that eggs are laid, parents raising smaller broods may eventually be favored over parents that risk failure by attempting large broods in poor years (Perrins and Moss, 1975; see also Murphy, 1968; Wilbur et al., 1974). Gillespie (1977) formalized a similar idea to demonstrate that selection can act on the variance in offspring production as well as on average production. Thus a smaller mean brood size is predicted if the success of larger broods is more variable than that of small broods. Results of this study suggest such a trend, but more data are needed.

The hypothesis of an inverse relationship between clutch size and adult survival (Williams, 1966; Charnov and Krebs, 1974 ) is an intuitively attractive modification of Lack's hypothesis and is often assumed despite inadequate evidence. This study failed to support this hypothesis and may illustrate potential problems in testing it experimentally.

Although differences in weight loss were not significant, female Tree Swallows raising experimentally enlarged broods tended to lose more weight than females with normal-sized broods. The trend is consistent with similar observations that have been interpreted as indicative of increased stress associated with rearing larger broods (Hussell, 1972; Winkel and Winkel, 1976). However, female weight loss during the breeding season may partially reflect normal regression of ovary and oviduct tissue (Ricklefs, 1974 and 1977), although this is more likely to be true early in the nesting cycle. This suggests more cautious use of weight changes as sufficient evidence of energetic stress due to reproduction (cf. Ricklefs, 1974 , p. 261), but neither are such changes irrelevant, as males may also lose weight during the nesting cycle (e.g., Bryant, 1979).

Weight changes among female Tree
Swallows were not paralleled by subsequent changes in survivorship. There was no indication that females rearing abnormally large broods survived less well than females raising normal-sized broods. However, return rates were higher than the $30-40 \%$ of previous years (Hussell, in LPBO Annual Report 1973; De Steven, unpubl. data). This may be a function of increasing colony age and more efficient trapping efforts in recent years (Hussell, pers. comm.), but it could also indicate an unusually favorable year for adult survival. Increased weight losses resulting from rearing larger broods could influence survival in poor years if females are stressed while molting and storing migratory fat reserves in the period following breeding.

Absence of a demonstrable reduction in survival of female Tree Swallows as a result of brood enlargement prompts two interpretations. First, demographic considerations suggest that the adjustment of clutch size in direct relation to adult mortality may not be as important a selective factor in species with high nonreproductive mortality as in species with low nonreproductive mortality (Ricklefs, 1973, p. 426; Charnov and Krebs, 1974). The argument is most easily applied to birds, since their annual survival appears to be relatively constant after maturity (Deevey, 1947; but see Botkin and Miller, 1974). A small reduction in a high annual adult survival rate (e.g., from $96 \%$ to $92 \%$, as in some seabirds) would correspondingly reduce life expectancy (and hence potential future breeding opportunities) from 24 years to 11.5 years (cf. Wooller and Coulson, 1977), whereas a similarly small reduction in a lower annual survival rate (e.g., from $75 \%$ to $72 \%$ ) would reduce life expectancy from 3 years to 2.6 years, a barely detectable change. Adult survival rates of temperate passerines such as the Tree Swallow range from 40 to $60 \%$ (Ricklefs, 1973); thus the results of this study could support the contention that a trade-off between clutch size and adult survival is not important in short-lived species.

However, a second and related issue is 
that even if one wished to argue that small changes in survival could be selectively important, one is faced with the problem of statistically demonstrating a difference between very similar survival rates, which would not be possible without extremely large samples. For example, a sample of $>200$ birds in each category would be needed to demonstrate a significant difference between the $58 \%$ return rate of Tree Swallow "control" females and the $67 \%$ return of "experimental" females ( $\chi^{2}$ test); a sample of 500 birds in each category is not sufficient to yield a significant difference between the $75 \%$ return of yearling "control" females and the $71 \%$ return of yearling "experimental" females (cf. Results). Thus there may be practical limitations to testing the hypothesis of an interaction between clutch size and parental survival in many species.

The absence of age-specific differences in breeding success and survival in response to brood enlargement despite clear differences in clutch size and laying date (De Steven, 1978) presents an interesting paradox. The success with which yearling female Tree Swallows reared extra young suggests that foraging inefficiency may be insufficient to explain the observed differences in breeding biology between yearling and older females (cf. De Steven, 1978). Other breeding features, such as the acquisition and defense of favorable nest sites, may also be influenced by experience and may exert indirect effects on age-specific breeding parameters (cf. Finney and Cooke, 1978).

In addition to the hypothesis tested here, other hypotheses attempt to account for mean brood sizes smaller than would be possible if food were the primary limiting factor as Lack originally believed. These include predation favoring rapid growth and short nesting periods (Skutch, 1949), selective advantages of reduced variance in breeding success (Gillespie, 1977), and intergenerational effects resulting in poorer reproductive performance of adults reared from large broods (Fretwell, 1969; Andersson, 1978). This study points out possible difficulties in testing one mod- ification of Lack's hypothesis; extended studies of specific populations will be needed to evaluate other hypotheses. Further complications will arise because the hypotheses are not mutually exclusive, and proposed factors may act simultaneously. The task ahead is to devise clear tests that allow distinction between alternatives, where possible. Satisfactory explanations are unlikely to be unitary, but will involve a multiplicity of factors that may vary in relative importance in particular cases.

\section{SUMMARY}

Modifications of Lack's hypothesis for the evolution of clutch size in nidicolous birds predict modal clutches smaller than the most productive, under the assumption that large broods stress parents and reduce subsequent parental survival. This hypothesis is tested for the Tree Swallow by comparison of breeding success, weight loss, and subsequent survival between females raising experimentally enlarged broods and females raising normal-sized broods. As age-specific differences in clutch size and laying date occur in this species, the effects of brood enlargement upon yearling females and upon older females are examined separately in order to test the related hypothesis that stress imposed by large broods should be more severe for inexperienced parents.

More young were fledged from enlarged broods than from normal-sized broods, but fledging rates of yearling and older female parents were similar. Brood enlargement resulted in greater variability in nestling growth rather than in poorer average growth. Methods of analysis attribute most of the variation in growth to differences among individual broods rather than among different brood sizes; this may reflect considerable variation in parental abilities. Among broods reared by yearling females, nestlings in larger broods were lighter in weight near fledging than in the smallest broods, but no such differences occurred among broods reared by older females. Mortality after fledging appeared to be independent of brood size. 
Females raising experimentally enlarged broods did not show significantly greater weight loss or poorer subsequent survival in comparison to females raising normal-sized broods, nor did yearling females appear more susceptible to stress than older females. These results are consistent with suggestions that the hypothetical trade-off between clutch size and adult survival plays a minor selective role in shaping the life histories of short-lived species; however, the results may also reflect practical problems in the detection of small but selectively important changes in survival in response to brood enlargement.

\section{ACKNOWLEDGMENTS}

I thank the Long Point Company for permission to work on Long Point, and the Long Point Bird Observatory for use of facilities and access to data collected by Observatory personnel, especially in 1978. The study could not have been completed without the assistance of S. Freyburger, who persevered with extraordinary tolerance. G. Miller and A. Rivers also provided additional help at critical times. $D$. Hussell contributed valuable advice and support. K. Fiala, P. Grant, H. Howe, D. Hussell, R. Payne, and R. Storer made helpful comments on the manuscript. The study was supported by a Frank $M$. Chapman Grant from the American Museum of Natural History. General support was also provided during the writing of this paper by the Division of Biological Sciences, University of Michigan, and by the Smithsonian Tropical Research Institute through a Noble Fund Fellowship in 1978.

\section{Literature Cited}

Andersson, M. 1978. Natural selection of offspring numbers: some possible intergeneration effects. Amer. Natur. 112:762-766.

Baldwin, S. P., AND S. C. KendeIGH. 1938. Variations in the weights of birds. Auk 55:416-467.

Botkin, D. B., AND R. S. Miller. 1974. Mortality rates and survival of birds. Amer. Natur. 108:181-192.

BRyANT, D. M. 1975. Breeding biology of House Martins Delichon urbica in relation to aerial insect abundance. Ibis 117:180-216.
1979. Reproductive costs in the House Martin (Delichon urbica). J. Anim. Ecol. 48:655675.

Chapman, L. B. 1935. Studies of a Tree Swallow colony. Bird-Banding 6:45-57.

Charnov, E. L., AND J. R. Krebs. 1974. On clutch-size and fitness. Ibis 116:217-219.

Cony, M. L. 1971. Ecological aspects of reproduction, p. 461-512. In D. S. Farner and J. R. King (eds.), Avian Biology. Vol. 1. Academic Press, N.Y.

Cowles, H. C. 1901. The physiographic ecology of Chicago and vicinity. Bot. Gaz. 31:73-108, 145-187.

DE Steven, D. 1978. The influence of age on the breeding biology of the Tree Swallow Iridoprocne bicolor. Ibis 120:516-523.

Deevey, E. S., JR. 1947. Life tables for natural populations of animals. Quart. Rev. Biol. 22:283-314.

FinNEY, G., AND F. Cooke. 1978. Reproductive habits in the Snow Goose: the influence of female age. Condor 80:147-158.

Fisher, R. A. 1958. The genetical theory of natural selection. 2nd ed. Dover, N.Y.

Forbush, E. W., AND J. B. MAY. 1939. Natural History of the Birds of Eastern and Central North America. Houghton Mifflin, Boston.

Fretwell, S. D. 1969. The adjustment of birth rate to mortality in birds. Ibis 111:624-627.

Gillespie, J. H. 1977. Natural selection for variances in offspring numbers: a new evolutionary principle. Amer. Natur. 111:1010-1014.

HaIls, C. J., AND D. M. Bryant. 1979. Reproductive energetics of a free-living bird. J. Anim. Ecol. 48:471-482.

Howe, H. F. 1976. Egg size, hatching asynchrony, sex, and brood reduction in the Common Grackle. Ecology 57:1195-1207.

HusSell, D. J. T. 1972. Factors affecting clutch size in Arctic passerines. Ecol. Monogr. 42:317364.

KLOMP, H. 1970. The determination of clutch size in birds: a review. Ardea 58:1-124.

KLUYver, H. N. 1963. The determination of reproductive rates in Paridae. Proc. 13th Inter. Ornithol. Congr., p. 706-716.

Kuerzi, R. G. 1941. Life history studies of the Tree Swallow. Proc. Linn. Soc. NY 52-53:1-52.

LACK, D. 1947. The significance of clutch size. Tbis $89: 302-352$.

-1966. Population Studies of Birds. Clarendon Press, Oxford.

MountFord, M. D. 1968. The significance of litter-size. J. Anim. Ecol. 37:363-367.

Murphy, G. 1968. Pattern in life history and the environment. Amer. Natur. 102:391-404.

O'ConNoR, R. J. 1976. Weight and body composition in nestling Blue Tits Parus caeruleus. Ibis 118:108-112.

Palmer, R. S. 1949. Maine birds. Bull. Mus. Comp. Zool. Harvard 102:1-656.

PAynter, R. A. 1954. Interrelations between 
clutch-size, brood-size, prefledging survival, and weight in Kent Island Tree Swallows. BirdBanding 25:35-58, 102-110, 136-148.

Perrins, C. M. 1965. Population fluctuations and clutch-size in the Great Tit Parus major. J. Anim. Ecol. 34:601-647.

. 1977. The role of predation in the evolution of clutch size, p. 181-191. In B. Stonehouse and C. M. Perrins (eds.), Evolutionary Ecology. Univ. Park Press, Baltimore.

Perrins, C. M., AND D. Moss. 1974. Survival of young Great Tits in relation to age of female parent. Ibis 116:220-224.

1975. Reproductive rates in the Great Tit. J. Anim. Ecol. 44:695-706.

Pianka, E. R., And W. S. Parker. 1975. Agespecific reproductive tactics. Amer. Natur. 109:453-464.

PINkowski, B. C. 1977. Breeding adaptations in the Eastern Bluebird. Condor 79:289-302.

RICKLEFS, R. E. 1968. Patterns of growth in birds. Ibis $110: 419-451$.

- 1973. Fecundity, mortality, and avian demography, p. 366-435. In D. S. Farner (ed.), Breeding Biology of Birds. Nat. Acad. Sci., Washington, D.C.

- 1974. Energetics of reproduction in birds, p. 152-292. In R. A. Paynter (ed.), Avian Energetics. Publ. Nuttall Ornithol. Club, No. 15. 1977. On the evolution of reproductive strategies in birds: reproductive effort. Amer. Natur. 111:453-478.
Skutch, A. F. 1949. Do tropical birds rear as many young as they can nourish? Ibis 91:430-455.

Sokal, R. R., AND F. James Rohlf. 1969. Biometry. W. H. Freeman and Co., San Francisco.

STEarns, S. C. 1976. Life-history tactics: a review of the ideas. Quart. Rev. Biol. 51:3-47.

STOCEK, R. F. 1970. Observations on the breeding biology of the Tree Swallow. Cassinia 52:3-20.

vON HAaRTMAN, L. 1967. Clutch-size in the Pied Flycatcher. Proc. 14th Inter. Ornithol. Congr., p. 155-164.

1971. Population dynamics, p. 391-459. In D. S. Farner and J. R. King (eds.), Avian Biology. Vol. 1. Academic Press, N.Y.

Wilbur, H. M., D. W. Tinkle, AND J. P. ColLINS. 1974. Environmental certainty, trophic level, and resource availability in life history evolution. Amer. Natur. 108:805-817.

Williams, G. C. 1966. Natural selection, the costs of reproduction, and a refinement of Lack's principle. Amer. Natur. 100:687-690.

Winkel, W., AND D. WINKEL. 1976. Über die brutzeitliche Gewichtsentwicklung beim Trauerschnäpper (Ficedula hypoleuca). J. Ornith. 117:419-437.

Wooller, R. D., and J. C. Coulson. 1977. Factors affecting the age of first breeding of the Kittiwake Rissa tridactyla. Ibis 119:339-349.

Corresponding Editor: H. M. Wilbur 